ELORE (ISSN 1456-3010), vol. $14-2 / 2007$.

Julkaisija: Suomen Kansantietouden Tutkijain Seura ry.

[http://www.elore.fi/arkisto/2_07/han2_07.pdf]

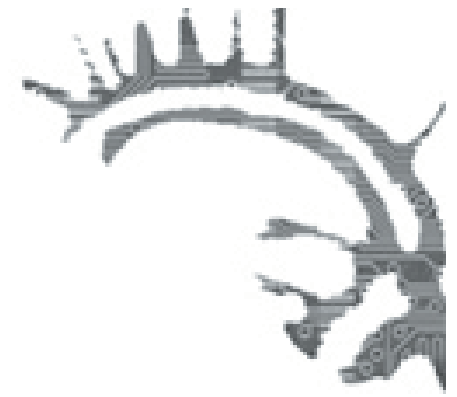

\title{
VAPAUDEN MERKITYS LUMILAUTAILUKULTTUURISSA
}

\section{Riitta Hänninen}

Lumilautailijoiden arkea ja arvoja tutkivana kulttuuriantropologina olen usein pysähtynyt miettimään, miksi nuoret ovat kiinnostuneita lumilautailusta. Kysymys on noussut esille erityisesti silloin, kun lumilautailijat puhuvat lumilautailukulttuuriin sisältyvästä vapaudesta ja sen tavoittelusta. Oman tutkimusaineistoni puitteissa vapaus toimiikin tulkinnallisena avainkäsitteenä, joka kokoaa yhteen ja antaa merkityksen useimmille lumilautailussa tärkeinä pidetyille arvoille.

Vapauden analyysissa keskityn tarkastelemaan sitä, millaisia asioita lumilautailijat tyypillisesti arvostavat valitsemassaan lajissa ja minkä he itse kokevat lumilautailussa tärkeäksi. Hedelmällisiksi ovat osoittautuneet myös sellaiset keskustelut, joissa tutkimukseeni osallistuneet laskijat kertovat lumilautailukulttuurissa ajankohtaisiksi kokemistaan ongelmista ja epäkohdista. Vapauden tavoittelu, oman toiminnan autenttisuutta käsittelevä pohdinta ja sitä edelleen käsitteellisellä tasolla jäsentävä ulkoisen tarkoituksettomuuden ideaali ovat lumilautailukulttuurin ideologisia perusaineksia. Tarkastelenkin tässä artikkelissa sitä, mitä lumilautailijat oikeastaan tarkoittavat puhuessaan vapaudesta.

Lumilautailun tekevät kiinnostavaksi sellaiset kulttuuriset käytänteet, joiden puitteissa laskijat erottautuvat tietyistä kielteisiksi kokemistaan instituutioista. Lumilautailun vaihtoehtoisuus avautuu lajia harrastavien ihmisten arkipäivässä erilaisten vapautta sivuavien tulkintojen, kuten kaupallisuuden, kulutuksen ja kilpaurheilun kautta. Näiden tulkintojen myönteisiksi vastinpareiksi nousevat esimerkiksi tyyli, tekemisen omaehtoisuus ja yksittäisen laskijan individualistisia pyrkimyksiä tukeva yhteisöllisyyden kaipuu. Kaupallistuminen - ja joissain tapauksissa myös kilpaileminen - määritellään lumilautailukulttuurissa kielteisiksi ilmiöiksi yleensä sen vuoksi, että niiden katsotaan vääristävän lumilautailuun alkuperäisesti kuuluvaa vapautta, jolloin laskija muuttuu aktiivisesta toimijasta markkinavoimien hallitsemaksi kuluttajaksi (Hänninen 2005, 39). Kaupallisuuden vastustaminen edustaa tässä lumilautailun autenttisuutta puolustavaa diskurssia, joka esittää laskijan henkilökohtaiset kokemukset muodin ja kaupallistuneen massan vastakohtana.

Nuorisokulttuureiden tutkimuksessa tyyli määritellään usein erottautumista palvelevaksi symboliseksi ilmaisuksi, joka antaa yhteisöllisyydelle visuaalisen tai muuten 
esimerkiksi musiikissa tai tilallisten kategorioiden välityksellä näkyvän muodon (ks. esim. Heiskanen \& Mitchell 1985; Gelder \& Thornton 1997). Lumilautailukulttuurissa vapauden tavoittelu voidaan aineistoni mukaan ymmärtää esimerkiksi tyylin kautta ilmaisunsa saavaksi asenteeksi. Lumilautailijoiden puheessa tyyli ja vapaus esiintyvät usein rinnakkaisina teemoina. Yksilöllisyyden ilmaisuna tyyli tarjoaa laskijalle kokemuksen vapaudesta esimerkiksi pukeutumiseen tai henkilökohtaiseen laskemisen tapaan viittaavana käsitteenä. Muodollisena ilmaisulajina tyylillä on kuitenkin aina myös tietty ideologinen, ja siten myös vapautta suoraan sivua sisältönsä, joka liittyy siihen millaisista asioista sen välityksellä halutaan puhua. Hieman yksinkertaistetusti voidaan siis todeta, että vapauden ideaali on yksi niistä tärkeistä arvoista, joita tyylillisen ilmaisun, kuten pukeutumisen ja musiikin, merkitystä lumilautailijat haluavat yleisellä tasolla kommunikoida. Käytännössä on kuitenkin niin, että nämä kaksi teemaa - vapaus ja tyyli - ymmärretään lumilautailijoiden keskuudessa toisiaan vastavuoroisesti selittäviksi käsitteiksi.

Itseilmaisun ideologisella eli tietyn kulttuurin arvoja koskevalla tasolla tyyli ja sitä seuraava erottautuminen voivat muuttua yksilöllisistä ilmiöistä lumilautailukulttuuria yhteiskunnallisesti selittäviksi tulkintakonteksteiksi. Yhteisöllisyyden perinteisten muotojen rinnalla elää länsimaisessa, globalisoituvassa maailmassa erilaisia vaihtoehtoisia elämäntapoja ja -tyylejä. Lumilautailukulttuurin tavoin ne eivät useinkaan tunnusta esimerkiksi perinteisiä valtio- tai kansallisuusrajoja, vaan ruokkivat paikallisten tulkintojensa välityksellä aikaisempaan verrattuna uusia tapoja jäsentää ympäröivää todellisuutta. (Vrt. Featherstone 1990,1-3). Lumilautaileminen ei ole sidoksissa laskijan kotimaahan tai kulttuuriin, vaan lumilautailukulttuurin mukana ympäri maailmaa levinneeseen arvojärjestelmään, jossa laskeminen nostetaan sekä kokemuksellisella tasolla että toimintana niin sanottujen perinteisten instituutioiden, kuten työn, perheen ja kodin, rinnalle osaksi lumilautailijoiden jokapäiväistä arkea.

\section{LUMILAUTAILIJAT OMAN KULTTUURINSA TULKKEINA}

Vapauden analyysi artikkelissa perustuu suomalaisten lumilautailijoiden parissa vuosien 2002-2003 välisenä aikana keräämääni kenttätyöaineistoon. Teemahaastattelujen $(\mathrm{n}=35)$ ja niiden pohjalta laatimieni kahden www-pohjaisen kyselylomakkeen ( $\mathrm{n}=$ 745) lisäksi olen kerännyt lumilautailukulttuurin julkisuuskuvaa suomalaisen lumilautailukulttuurin alkuajoilta, vuodesta 1989 lähtien nykyhetkeen saakka valaisevaa artikkeliaineistoa, jota sivuan tässä analyysissa tosin vain lyhyesti (1). Artikkeliaineiston perusteella voidaan sanoa, että lumilautailun julkisuuskuvassa on tapahtunut viimeisten parinkymmenen vuoden aikana selkeä muutos. Ilmiö, josta vielä 1960- ja 1970-luvuilla Yhdysvalloissa puhuttiin lasten leikkikaluna, oli muuttunut Suomessakin 1990-luvun alkupuolella, jolloin laji vakiintui maassamme, nuorisokulttuuriseksi marginaali-ilmiöksi. Artikkeliaineiston perusteella ja lajin julkisuuskuvaa vasten näyttää myös siltä, että lumilautailun laajempi suosio ajoittuu Suomessa 1990-luvun loppuun ja 2000-luvun alkuun. (Vrt. Mannermaa 2004.) 


\section{RIITTA HäNNINEN}

Ammattilaisten ja muiden lumilautailukulttuurin hyväksi työskentelevien laskijoiden ohella tutkimuksessani on mukana paljon erilaisia harrastuksenaan lautailevia ihmisiä. Lähestulkoon kaikki teemahaastatteluissa ja kyselylomakkeissa mielipiteensä julkituoneista laskijoista määrittelivät itsensä lumilautailijoiksi. Omalta osaltaan tämä johtuu todennäköisesti siitä, että en halunnut kenttätyöni alkuvaiheessa rajoittaa tutkimukseen osallistuvien laskijoiden joukkoa omien ennakkokäsitysteni perusteella vaan pyysin vastauksia kaikilta niiltä ihmisiltä, jotka itse kyseisellä hetkellä kokivat olevansa lumilautailijoita.

Oma huomioni on, että lumilautailukulttuuriin ideologisella tasolla liitetyt merkitykset ovat huomattavan samansuuntaisia riippumatta laskijan iästä, sukupuolesta tai lautailuhistoriasta. Lumilautailijat pitävät tärkeänä esimerkiksi sitä, että lumilautailua harrastetaan lumilautailun itsensä vuoksi eikä esimerkiksi jonkin ulkopuolisen päämärän, kuten lajin trendikkyyden houkuttelemana. Erityisesti vapauden teema esiintyy aineistossa yleisenä lumilautailemiseen liitettynä arvona, vaikka siihen liitetyt merkitykset vaihtelevatkin lautailijasta toiseen.

Lomakekyselyaineisto (L1 ja L2) pohjautuu teemahaastattelurunkoon, jolla alun perin aloitin tutkimukseni (2). Teemahaastatteluvaiheen alussa, keväällä 2002, kiinnitin haastattelutilanteissa huomiota myös teemahaastattelurungon tarkoituksenmukaisuuteen lumilautailijoiden näkökulmasta; lumilautailijat pääsivät itse vaikuttamaan haastattelurungon rakenteeseen. Lomakkeeseen 1 (L1) valitsin myöhemmin sellaiset kysymykset, jotka ovat mielestäni olennaisia silloin, kun halutaan tietää, miksi lumilautaileminen on lumilautailijoille tärkeää, ja edelleen, millaisin keinoin he haluavat tuoda valintansa esille erilaisten ilmaisulajien, kuten pukeutumisen kautta.

Kyselyni osoittautui www-ympäristössä varsin suosituksi sillä seurauksella, että aineisto alkoi pian toistaa itseään. Tämän vuoksi koostin uuden kysymyslistan (L2) teemahaastattelurungon muista osista ja täydensin sitä tutkimusprosessin aikana muodostuneilla uusilla kysymyksillä. Toiseen lomakkeeseen valikoituneet kysymykset täydentävät alkuperäisen teemahaastattelurungon keskeisiä teemoja. Kaikki kolme mainittua aineistoa ovat alkuperäisen kysymyksenasettelunsa vuoksi sisällöllisesti hyvin samansuuntaisia, ja siksi olen käsitellyt niitä myös tämän artikkelin osalta toisiaan tulkinnallisesti täydentävinä kokonaisuuksina.

Aineistoni on laaja, joten olen ryhmitellyt sen temaattisiksi kokonaisuuksiksi. Käytännössä olen ensin lukenut koko aineiston läpi, jäsentänyt sen teemoihin ja muodostanut näin itselleni käyttökelpoisen tutkimusmateriaalin. Artikkelini kannalta keskeisiä aineistosta esille nousevia teemoja ovat juuri vapaus ja tyyli. Kun olen tällä tavalla kartoittanut lumilautailuun liittyviä merkityksiä, olen siirtynyt teemojen analyysiin. Artikkelissani esiintyvät aineistositaatit edustavatkin sellaisia esimerkkejä, jotka kuvaavat mielestäni erityisen valaisevalla tavalla vaikkapa jotakin vapauden kokemuksen kannalta tyypillistä perusteemaa. (Vrt. Hänninen 2004.)

Lumilautailijoiden joukko on muuttunut lajin popularisoitumisen myötä aikaisempaa heterogeenisemmaksi, ja siksi kulttuurista merkkienlukutaitoa ohjaava sosiaalinen hierarkia vaikuttaa entistä voimakkaammin siihen, miksi yksittäinen laskija kokee lumilautailemisen itselleen tärkeäksi. Käsillä olevassa analyysissa tämä ilmiö näyttäytyy lumilautailijoiden omaan toimintaansa liittämien merkitysten moninaisuu- 
tena. Muutoksen teeman äärelle olen päätynyt myös omaa tutkijapositiotani käsittelevissä pohdinnoissa. Lumilautaileminen on vanha harrastukseni, vaikka varsinaisista aktiivivuosista laskemisen parissa onkin jo kymmenen vuotta aikaa. Lautailutausta on auttanut minua tutkijana ymmärtämään monia sellaisia asioita, joita en ehkä muuten olisi osannut etsiä tutkimuskentältäni. Liikuntamuotona lumilautailemiseen liittyy esimerkiksi ruumiillisuus ja liike, joihin on vaikea samastua ilman henkilökohtaista kokemusta. Tulkinnallista merkitystä on mielestäni myös sillä, että tunsin lumilautailijoita haastatellessani myös jonkin verran laskemiseen liittyvää perussanastoa.

Vanhan harrastuksen ohella lumilautaileminen on myös tutkimuskohteeni, jota nyt siis tarkastelen tässä hetkessä ikään kuin ulkopuolisen silmin entisenä lumilautailijana. Eläytymistä seuraa antropologisessa tulkinnassa aina etääntyminen, tai näin kaiketi ainakin pitäisi olla. Erilaiset itsestäänselvyydet ovat osa tutkimusprosessia erityisesti silloin, kun antropologi työskentelee oman kulttuurinsa parissa. Etääntymisen ymmärrän tässä kohtaa näiden itsestäänselvyyksien kyseenalaistamisena syvemmän tulkinnan muodostamiseksi. Lähdekritiikin kannalta edukseni on koitunut, että vaikka tutkinkin itselleni ennestään tuttua ilmiötä, lumilautaileminen on ehtinyt muuttua viimeisen kymmenen vuoden aikana niin, että ajallinen etäisyyteni lajiin entisenä harrastajana on tullut etääntymisen avuksi.

\section{VAPAUS LUMILAUTAILUN IDEOLOGISENA KULMAKIVENÄ}

Erään tutkimukseeni osallistuneen laskijan mukaan "lumilautailu symbolisoi vapautta, jonka voi vain kokea lautailussa itsessään" (L2: 501, M80). Sitaatissa kuvailtu ilmiö muistuttaa läheisesti leikkiä, jonka leikkitutkimuksen klassikkohahmo ja kulttuurihistorioitsija Johan Huizinga näkee teoksessaan Leikekivä ibminen (1947) ensisijaisesti juuri vapauden tavoittelun kautta jäsentyvänä toimintana: "Pakollinen leikki ei ole enää mitään leikkiä [...] Siihen ei ryhdytä fyysisestä välttämättömyydestä, vielä vähemmän siveellisestä velvollisuudesta. Se ei ole mikään tehtävä.” (Huizinga 1947, 16-17.)

Leikin ja siihen liittyvän vapaudentavoittelun läheinen suhde nousee lajia yleisemmin määrittäväksi tulkintakontekstiksi myös folkloristi Olav Christensenin norjalaisia lumilautailijoita käsittelevässä tutkimuksessa (2002; 2001a; 2001b). Artikkelissaan "Playing Collective. Snowboarding, Youth Culture and the Desire for Excitement" (1999) Christensen tarkastelee lumilautailua sosiologi Roger Cailloisin klassikkoteoksessa Man, Play and Games (1961) esiintyvän nelijaon puitteissa. Caillois on Huizingan kanssa samaa mieltä siitä, että leikki on vapaata, epävarmaa, säännönmukaista, taloudellisesti kannattamatonta ja ainakin osittain mielikuvitukseen perustuvaa, mutta yhtäkaikki reaalista toimintaa (Hänninen 2003, 109). Varsinaisiksi leikkikategorioiksi Caillois määrittelee kilpailemista, taitoa ja voittamista painottavan agônin, erilaiset sattuman ja onnen kanssa tekemisissä olevat pelit, joita Caillois kutsuu termillä alea, sekä näyttelemistä ja jäljittelyä korostavan mimicryn. Neljäntenä leikkikategoriana tässä asetelmassa tulee erilaisia epätasapainotiloja luova ilinx , joka yleensä viittaa ulkoisilta tunnuspiirteiltään extreme-urheilullekin tyypillisiin kokemuksiin, kuten liukumiseen, pyörimiseen ja vauhtiin. 


\section{RIITTA HäNNINEN}

Olav Christensenin rakentama vertailuasetelma leikin ja lumilautailun välillä on mielestäni valaiseva esimerkki siitä, että leikkitutkimuksen klassikoilla, kuten Johan Huizingalla ja hänen tuotantoaan omassa ajattelussaan soveltaneella Roger Cailloisilla voi olla paljonkin annettavaa esimerkiksi nykyhetken ilmiöistä kiinnostuneelle nuorisokulttuureiden tutkimukselle. Olav Christensen on osoittanut tutkimuksessaan muun muassa, että lumilautaileminen on monella tavalla, joskaan ei välttämättä aina, kilpailullista toimintaa (agôn), johon liittyy lisäksi extreme-urheilulle tyypillinen jännitys ja vauhdin hurma (alea ja ilinx). Fiktiivisen eli jäljitellyn todellisuuden (mimicry) maailmaan lumilautailijat siirtyvät Christensenin mukaan esimerkiksi samastuessaan lumilautailijoiden parhaimmistoa edustaviin ammattilaskijoihin. (Christensen 2001a; 2001b; 1999.)

Huizingan ja Cailloisin leikkikäsityksiä yhdistävänä teemana voidaan pitää sitä, että ne korostavat molemmat vapauden merkitystä yhtenä kulttuurisen leikin keskeisistä elementeistä. Keskeistä tässä asetelmassa on käsillä olevan artikkelin kannalta ensinnäkin se, että Cailloisin leikkiteorian nelijaossa mainitut teemat ovat yleisiä myös tutkimukseeni osallistuneiden lumilautailijoiden arvomaailmassa, ja siksi ne ovat näkyvästi esillä myös artikkelin alalukujen jäsennyksessä. Toisena tärkeänä seikkana on kuitenkin mainittava, että puhuessaan esimerkiksi ilinxiin tai agônïn liittyvistä kokemuksistaan, kuten jännityksestä ja kilpailemisen merkityksestä lumilautailukulttuurissa, tutkimukseeni osallistuneet laskijat määrittelevät lumilautailemisen vain harvoin leikiksi. Leikin sijaan tärkeämpää näyttää olevan vapaudentavoittelu, johon lumilautailijat viittaavat käsitteenä joko suoraan tai välillisesti erilaisten vapauden kokemusta kuvaavien henkilökohtaisten esimerkkien kautta. Omassa tutkimuksessani näyttää Christensenin soveltaman nelijaon puitteissa lisäksi siltä, että se ei kykene kaikilta osin kuvaamaan oppimisen merkitystä yhtenä lumilautailijoille tärkeänä vapauden ilmenemismuotona.

\section{LUMILAUTAILUKULTTUURI ENNEN JA NYT}

Lumilautailukulttuurin historialliset vaiheet ovat sidoksissa surffaukseen ja rullalautailuun eli skeittaukseen, jota kalifornialaiset surffarit harrastivat 1950- ja 1960-lukujen Yhdysvalloissa silloin, kun sääolosuhteet eivät suosineet lainelautailua. (Pearson 1979, 31-32.) Vaikka lumilautaileminen oli vielä 1980-luvulle tultaessa useimmissa laskettelukeskuksissa ympäri maailman kiellettyä, oli taloudellisten vaikeuksien keskellä tuolloin painiskelleiden rinneyrittäjien suhtautumisessa jo tapahtumassa lumilautailijoiden kannalta myönteisiä muutoksia. (Humphreys 1997, 152.) Suomalaisiin tiedotusvälineisiin lumilautailu ilmestyi 1980-luvun puolivälin tienoilla, jolloin uutta lajia esiteltiin talviurheilusta kiinnostuneille muun muassa laskettelijoita palvelevan Skimbaaja-lehden $(1984,39)$ sivuilla:

Snowboarding on lainelautailun ja monoski-hiihdon risteytys, jota harrastetaan puuterilumessa hiihtoasusteisiin pukeuduttuna. Lajista on tullut 


\title{
VAPAUDEN MERKITYS LUMILAUTAILUKULTTUURISSA
}

uusi villitys vannoutuneiden puuterinpöllyttäjien keskuudessa: suosio on helposti ymmärrettävissä katsottaessa filmejä lainelautailusta: snowboarding on täysin vastaavaa touhua talvisissa oloissa ilman päällesortuvia tappavan vaarallisia maininkeja.

Varsinaisen läpimurtonsa lumilautaileminen teki Suomessa 1990-luvun alkupuolella, jolloin yhä useammat nuoret vaihtoivat laskettelusuksensa lumilautaan. Jännitys ja vauhdikkuuden mukanaan tuoma vaara korostavat eksotiikkaa ja nuorisokulttuuristen ilmiöiden "länsimaista toiseutta" samalla, kun ne rinnastavat lumilautailukulttuurin muihin viime vuosina yhä näkyvämmiksi muuttuneisiin extreme-lajeihin. Extreme-urheilun nykymuodot palaavat 1960-luvulla voimistuneeseen The New Leisure Movement -suuntaukseen, jossa perinteisen urheilun rationalistiset ja byrokratisoituneet muodot saivat rinnalleen liikkumisen luovuutta korostavan ideologian (Humphreys 2003, 411). Vastaava painotus on nähtävillä myös lumilautailukulttuurissa, jossa suorituskeskeisyys ja urheilun funktionalistiset eli vallitsevaa yhteiskuntajärjestystä esimerkiksi sosialisaation muodossa ylläpitävät merkitykset ovat korvautuneet hauskanpitoa, itseilmaisua ja tekemisen omaehtoisuutta korostavilla tulkinnoilla (vrt. Humphreys 1996, 13). Lumilautailemisen lisäksi myös surffaus, rullaluistelu, laskuvarjohyppy, kiipeily, skeittaus ja bmx-pyöräily ovat esimerkkejä juuri sellaisista "perinteisen urheilun tuolle puolen" (vrt. Hänninen 2005) kurottavista lajeista, joita rullaluistelua tutkinut Robert Rinehart kuvaa urheilun uusiksi, vaihtoehtoisiksi muodoiksi $(2003,27)$.

\section{"Jos SÄ MEET, MÄKIN YRITÄN" - OPPIMISEN RIEMU JA VAPAUS}

\author{
Itse en helposti opi unsia asioita, samaa pitäa jankata aika kauan. Mutta se on \\ mabtava tunne kun asian todella saa onnistumaan ja kuulee kavereiden hurraavan. \\ Yksin on vaikea snonkata, joten tavallaan lumilautailu on myös yhdistävä laji, \\ siinä saa viettää aikaa frendien kanssa ja aina oppii jotain untta kun tapaa unsia \\ ibmisiä. (L1: 116, N85.)
}

Paremmaksi lumilautailijaksi tuleminen on lumilautailukulttuurissa yleisesti arvostettu tavoite, joka esiintyy sosiaalisen hierarkian kaikilla tasoilla. Ammattilaskijat kilpailevat itseään ja toisiaan vastaan kansainvälisissä kilpailuissa ja muilla julkisilla areenoilla. Paremmaksi lumilautailijaksi tulemisen kaipuu ajaa yleisesti myös paikallisrinteiden kaveriporukoita ja jopa sosiaalisessa hierarkiassa alimpana olevia harrastelijoita, joille laskutaitojen kehittäminen on usein nimenomaan henkilökohtaiseen oppimisen riemuun liittyvä tavoite. Uusien asioiden oppiminen kiinnittyy tässä asetelmassa oman itsensä ylittämistä korostaviin tulkintoihin. Tapahtumana se on osa prosessia, jossa lumilautailija muuttuu aikaisempaan verrattuna taidoiltaan paremmaksi tai monipuolisemmaksi laskijaksi (vrt. Hall 1999). Liikkumisen vapaus ja ilmaisun monipuolisuus ovat tämän tulkinnan mukaan sitä laajempia, mitä taitavammasta laskijasta on kysymys. Varsinaiseen vapauden kokemukseen laskijan taitotaso ei tässäkään kohtaa 


\section{RIITTA HäNNINEN}

kuitenkaan suoraan vaikuta. Liikkumisen vapaus on lumilautailukulttuurissa yksilön henkilökohtaisiin taitoihin kiinnittyvä kokemus, joka korostaa oppimisen merkitystä yhtenä lumilautailijoiden omaan tekemiseensä liittämänä perusarvona.

Kaveriporukat edistävät uusien asioiden oppimista tarjoamalla lumilautailijoille kannustavan ja välittömän ilmapiirin omien taitojen parantamiseksi. Oman laskemisen kehittämisessä tarvitaan muiden laskijoiden tukea joko suoraan lumilautailijalta lumilautailijalle tai välillisesti ammattilaskijoiden tarjoamien esikuvien kautta. Yksin laskeminen tarjoaa monille laskijoille oman harmonisen, esimerkiksi luonnossa liikkumiseen liittyvän nautintonsa, mutta samanaikaisesti muiden laskijoiden tukea pidetään edelleen yhtenä oppimisen peruselementtinä. Christensen (1999, 117: vrt. Gothóni 1997, 142-143) kuvaa ammattilaskijoiden ja paikallisrinteissä laskevan lumilautailukansan välistä suhdetta "jäljitteleväksi ymmärtämiseksi" (engl. mimetic understanding), jossa rivilaskijat jakavat lautailuleffasta tai lehden sivuilta poimitun suorituksen vertaamalla sitä omiin henkilökohtaisiin laskukokemuksiinsa.

Kuvallisen ilmaisun merkityksestä lumilautailukulttuurissa kertoo omalta osaltaan myös niin sanottujen kotitekoisten lautailuleffojen yleistyminen. Omakohtaisessa tekemisessä ilmaisunsa saava autenttinen kokemus välittyy muille lumilautailijoille juuri visuaalisesti filmien ja valokuvien välityksellä. Samastumiseen ei välttämättä tarvita edes kielellisen ilmaisun verbaalista tasoa: ruumiillisuus ja siihen kommunikatiivisesti liittyvät aspektit, kuten pukeutuminen ja muu tyylillinen ilmaisu, puhuvat yhteisöllisyyden sanatonta kieltä.

Ammattilaisuuden lisäksi lumilautailun parista löytyy myös muita rooleja, joiden kautta laskijat voivat osallistua lumilautailukulttuurin kehittämiseen. Keskeisintä oman paikan löytämisessä on se, että lumilautailua harrastetaan jokaisen henkilökohtaisista lähtökohdista käsin laskijan itse omalle toiminnalleen asettamien tavoitteiden puitteissa. Kokonaisuutena hyvän lumilautailijan muotokuva sisältää tutkimukseeni osallistuneiden lumilautailijoiden mukaan myös teknisiin ja sosiaalisiin taitoihin liittyviä ominaisuuksia. Kaveripiirin ja muiden kanssalaskijoiden arvostamaa hyvää lumilautailijaa kuvataan tyypillisesti rohkeaksi, taitavaksi, monipuoliseksi ja tyylikkääksi laskijaksi, joka tulee toimeen kaikkien kanssa ja toteuttaa itseään omaehtoisuuden hengessä koko lumilautailukulttuurin yhteisen hyvän puolesta. Taitava laskija hallitsee välineensä kaikissa tilanteissa sääolosuhteista tai rinteiden kunnosta riippumatta. Hyvä lumilautailija tuntee omat rajansa ja kykenee lisäksi arvioimaan itsestään riippumattomien muuttujien, kuten maaston tai muiden rinteessä liikkujien, vaikutusta omaan suoritukseensa.

Jokaisella laskijalla on oma tyylin käsitettä välillisesti sivuava tapansa liikkua ja laskea, mutta vasta henkilökohtaiset kokemukset ja ennen kaikkea kokeneisuus tekevät lautailemisesta paitsi esteettisesti myös sanan omaehtoisuuteen viittaavassa merkityksessä aidosti tyylikästä. Kokonaisuutena näyttääkin siltä, että tyyli heijastaa laskijan yleistä asennoitumista lumilautailemiseen ja kertoo näin muille lautailijoille, onko tekeminen aitoa vai ei. Kokenut laskija voi esimerkiksi hallita tietyllä hetkellä suosittujen temppujen repertoaarin, mutta se ei riitä. Aidon ja muiden laskijoiden arvostaman lumilautailijasta tekee juuri omaperäisyys ja ennen kaikkea aito laskemisen ilo. Tyyli on osittain myös makukysymys. Osa laskijoista arvostaa esimerkiksi van- 
haa 1980-luvulta tuttua ilmaisua (engl. old school) tai vapaalaskua toisten keskittyessä "new schoolina" tunnetun uuden koulukunnan tarjoamiin haasteisiin. Pukeutumisessa, laskemisen tavassa ja asenteessa ilmaisunsa saavaan tyyliin vaikuttavat myös monet musiikilliset suuntaukset (rock, punk, hiphop) sekä toisaalta muut lautailu- ja extreme-lajit, joita harrastetaan vuodenkierron mukaan usein lumilautailemisen kanssa rinnakkain tai sen vaihtoehtona.

\title{
Polvet Rentoina ja POKKA PITÄÄ RIITTÄÄ - RISKINOTtTOA JA VAARALLISIA TILANTEITA
}

\author{
Serkku buomasi byvännäköisen nyppylän josta voisi kokeilla bypätä jotakin tyyli- \\ kästä. Nyppylän takana ollut kunsi jäi huomaamatta. Sinne kosabti roikekumaan \\ laudasta pää alaspäin. Ja kyllä nauratti. (L1:12, M74.)
}

Oppimisen ideaalia omassa lautailemisessaan toteuttavat "tosilaskijat" käyttävät laskettelurinteiden tarjoamaa tilaa eri tavalla niin sanottuihin harrastelijoihin verrattuna. Mielikuvituksella ei ole tämän diskurssin mukaan periaatteellisia rajoja, sillä kaikkea voi ja suorastaan pitäk̈kin laskea. Suorituspaikat ovat aktiivisessa käytössä, ja usein lisäjännitystä haetaan myös rinteiden ulkopuolelta, metsäreiteiltä, hyppyreistä, reileistä (engl. hand rail) ja paipeista (engl. half pipe) (3). Virallisten laskettelurinteiden ulkopuolella kuten kaupungeissa lumilautailemiseen liittyy rullalautailusta omaksuttuja vaikutteita. Kaiteet, portaat ja erilaiset pudotukset suosivat näyttäviä temppuja, joiden extreme-laatu ei tosin perustu vauhdin hurmassa pöllyävään puuterilumeen vaan ahtaiden, vähälumisten ja sen vuoksi erittäin riskialttiiden suorituspaikkojen tuottamaan jännitykseen.

Uuden asian opetteleminen on lumilautailemisessa samoin kuin extreme-urheilussa yleisemmälläkin tasolla konkreettinen hyppy tuntemattomaan, tutun ja turvallisen tuolle puolen. Tuntemattoman edessä koettu epävarmuus on pelkoa ruumiillisen hyvinvoinnin puolesta. Huolta kannetaan tapaturmista ja äärimmilleen vietynä jopa kuolemasta. Taitojensa äärirajoilla liikkuvat laskijat ottavat rinteissä tietoisia riskejä. Näin siitäkin huolimatta, että hyvää lumilautailijaa kuvataan tässä suhteessa myös vastakkaisin termein maltilliseksi laskijaksi. Tasapainottelu riskien ja turvallisuuden välillä on osa omien rajojen koettelemista, ja siksi eriasteiset tapaturmat ovat lumilautailun maailmassa suhteellisen yleisiä. Pienempiä kaatumisia kuvataankin usein oppimiseen liittyvänä välttämättömyytenä: mustelmat ja ruhjeet kertovat tapaturman vakavuudesta riippuen joko hauskalla tai pelottavalla tavalla laskijan rohkeudesta kokeilla uusia asioita. Ruhjeet ovat konkreettisia muistoja menneistä tapahtumista, joista on vaaratilanteesta huolimatta lopulta selvitty ja joista on tulevien talvien varalle ehkä jopa opittu jotakin uutta. Lautailulehtien sivuilla tapaturmat esitetään osana ammattilaskijoiden työtä ja katu-uskottavuutta. Jutuissa kerrotaan tapaturmaan johtaneista olosuhteista, vammojen vakavuudesta ja siitä, miten nopeasti laskijan arvioidaan pääsevän takaisin yhteisen harrastuksen pariin. 


\section{RIITTA HäNNINEN}

Lumilautaileminen oli laskettelukeskuksissa ympäri maailman pitkään, 1990luvun vaihteeseen saakka kokonaan kiellettyä, ja tämän jälkeenkin lumilautailijoiden liikkumista pyrittiin rajoittamaan niin, että rinteiden laskettelijat laskettelurinteiden varsinaisena asiakaskuntana asetettiin usein lumilautailijoiden edelle. Rajoituksia perusteltiin turvallisuusriskeillä, mutta käytännössä mukana oli myös lumilautailijoiden tavanomaisesta poikkeavaan pukeutumiseen ja käyttäytymiseen liittyviä ennakkoluuloja. Merkille pantavaa viidentoista vuoden takaisessa turvallisuuskeskustelussa on se, että kritiikki suuntautui tuolloin pääsääntöisesti lumilautailijoita ja lumilautailukulttuuria vastaan. Nykypäivänä huomion keskipiste on siirtynyt laskettelijoiden oikeuksista lumilautailijoiden henkilökohtaista turvallisuutta sivuaviin teemoihin:

[...] ei mulla omaa kypärää oo, mutta jos joku sellasen antas, niin kyllä mä ottasin, tottakai päätäpitää suojata. Mut sitpaljon vahvemmat mielipiteet mulla on, että mitä mieltä mä oon kaikesta, että jos joku on pakollista. ... jos joku kattoo aibeelliseksi käyttää kypärää, nïn sitten se käyttää kypärää ja nykyään trendi on aika byvä, mutta tebkää siitä trendi, älkääkä tebkö sïtä sääntöö. (T30, M78.)

Osa lautailukilpailuja järjestävistä organisaatioista, esimerkiksi Kansainvälinen Hiihtoliitto, on määritellyt kypärän pakolliseksi turvavarusteeksi. Kaikki lumilautailijat eivät kuitenkaan hyväksy tätä sääntöä. Keskeiselle sijalle konfliktissa nouseekin juuri omaehtoisuuden ylittävä pakko, joka on vieläpä lumilautailukulttuurin ulkopuolelle jäävän instituution asettama. Trendin ja säännön erottaa tämän tulkinnan mukaan toisistaan vapaaehtoisuuden aste. Trendinä lumilautailija voi halutessaan lisätä kypärän varustukseensa ja sitä kautta omaan tyyliinsä, mutta sääntönä kypärä rikkoo omaehtoisuuden ja siten myös vapauden ideaalia vastaan.

Jäljittelevä ymmärtäminen (engl. mimetic understanding) estetisoi tapaturmat ja liittää ne näin osaksi lumilautailukulttuurin kollektiivista merkitysjärjestelmää (Christensen 1999, 117). Lumilautailulehtien ja -elokuvien välityksellä kuka tahansa, jopa laskemisen vastikään aloittanut harrastelija, voi ihailla maailman korkeimman vuoren laelta avautuvaa lumista maisemaa tai laskeutua näyttävän tempun sulavasti ilman pienintäkään horjahdusta ja tuntea itsensä näin osaksi lumilautailijoiden globaalia yhteisöä. Hauskuus, jännitys ja pelko ovat lumilautailussa usein vain sentin tai sekunnin murto-osan päässä toisistaan. Tapaturmien estetisoituminen tarjoaa konkreettiseen tapahtumaan kiinnittyvän esimerkin jäljittelevän ymmärtämisen tuottamasta vaihtoehtoisesta maailmasta, joka romantisoi extreme-urheilulle liitetyn vaaran ja esittää riskien ottamisen esimerkiksi osana ammattilaskijoiden arkea tavoittelemisen arvoisena toimintana. Vaaran estetisoituminen palvelee oppimista: se kannustaa kokeilemaan uusia asioita. Jäljittelevä ymmärtäminen selittää myös lumilautailemisen kaupallista suosiota, sillä se tarjoaa mainoksia seuraavalle kuluttajalle myönteisiä samastumiskohteita. 
VAPAUDEN MERKITYS LUMILAUTAILUKULTTUURISSA

\title{
TYHMÄ IHANA KILPAILEMINEN
}

\begin{abstract}
Jotenkin ne [kilpailut] sotivat lumilautailun perusperiaatteita vastaan. Varsinkin sellaiset, joissa todella kilpaillaan sanan varsinaisessa tarkoituksessa, mutta mikäli "kisat" ovat vain "kisat" että sinne mennään siksi että siellä on kaverit/ystävät joidenka kanssa pidetään hauskaa ja kilpaileminen on vain sivutuote nïn sellaiset jotenkin menee. Mutta kilpailut joissa voittaminen on pääasia saa mielestäni kieltää vaike. beti. (L1: 125, N83.)
\end{abstract}

Lumilautailun half pipe oli lajina yksi Suomen selkeimmistä ennakkosuosikeista Salt Lake Cityn talviolympialaisissa vuonna 2002. Suomalaisittain synkäksi muodostuneet Lahden maailmanmestaruuskilpailut olivat dopingrikkomustensa vuoksi vielä tuoreessa muistissa, ja perinteiset talviurheilulajit hakivat tiedotusvälineissä entistä paikkaansa. Kilpaurheilun päämääränä on olympialiikkeen iskulauseen mukaisesti tehdä asiat "nopeammin, voimakkaammin ja korkeammalle". Ihmisruumiin rajoja koetellaan kilpaurheilussa joka päivä, eikä lumilautaileminen muodosta tässä suhteessa poikkeusta. Kilpailemisen etiikkaan lumilautailukulttuurissa sen sijaan suhtaudutaan perinteiseen urheiluideologiaan verrattuna poikkeavalla tavalla.

Lumilautailukulttuurin historiassa on runsaasti viittauksia lajin kilpailulliseen luonteeseen. Itse asiassa virallisten laskettelukeskusten ulkopuolella metsäisillä rinteillä järjestetyt kilpailut toivat lumilautailijat aluksi yhteen ja loivat lumilautailukulttuurille sen yhteisöllisen perustan. Tapahtumia kuvataan yhä edelleen myönteisessä sävyssä samanaikaisesti, kun perinteistä voitontavoitteluun perustuvaa kilpailemista kritisoidaan voimakkaasti. Näyttääkin siltä, että kilpailun ideologia on jakautunut lumilautailukulttuurissa kahtia. Lautailijoiden omissa tapahtumissa, esimerkiksi olympialaisia boikotoivan lautailijalegenda Terje Haakonsenin järjestämässä Arctic Challenge -kilpailussa, tavataan muita lautailijoita ja pidetään hauskaa. Laskijan aikaisemman menestyksen perusteella kutsutilaisuutena järjestetty Arctic Challenge edustaa suoraa jatkumoa alkuvuosien omaehtoisuuteen perustuvalle kilpailuperinteelle.

Toisena tässä asetelmassa tulevat maailmanlaajuisten kilpailuorganisaatioiden, kuten Kansainvälisen Hiihtoliiton, järjestämät kilpailut, joita tutkimukseeni osallistuneet lumilautailijat pitivät tyypillisesti liian kaupallisina ja siksi epätoivottavina tapahtumina. Hyväksyttävää kilpaileminen on näiden kahden maailman välissä, jos se ei muodosta koko lajia hallitsevaa pääasiaa vaan hauskan tapahtuman, jossa voi tavata muita samanhenkisiä ihmisiä ja viettää aikaa heidän kanssaan.

Kun kilpaileminen palvelee yhteisöllisyyden rakentumista, ovat vertailukohtana muut laskijat tai vaihtoehtoisesti lumilautailijan omat henkilökohtaiset suoritukset. Puhtaasti voittamisen vuoksi järjestetyt kilpailut sen sijaan rikkovat sisäisen motivaation periaatetta vastaan, jolloin laji muuttuu ulkopuolisia päämääriä palvelevaksi välineeksi. Lumilautailu esiintyy myös tässä tulkintakontekstissa työn vastakohtana, ei tosin suoraan sellaisenaan vaan vapaa-ajan kentän kautta yhtenä rentoutumisen muotona. Välineellistymiseen liitetyt kielteiset merkitykset kiteytyvät juuri näissä, "perinteistä kilpaurheilua" kritisoivissa kannanotoissa. Niiden mukaan kilpailemisen kaupallistuneet 


\section{RIITTA HäNNINEN}

muodot riistävät lumilautailijoilta heille kuuluvan itsemäärittelyoikeuden korvaamalla sen omilla päämäärillään.

Uusien asioiden oppiminen on tärkeä osa lumilautailukulttuurin kilpailullista ideologiaa. Itsensä ylittämisen suhde länsimaisen yhteiskunnan vallitseviin järjestyksiin on luonteeltaan metaforinen: lautailijoilla on vapaus valita kahden toisistaan poikkeavan merkitysjärjestelmän välillä ja tehdä maailma tämän valinnan kautta omakseen. Keskeisen sijan tässä asetelmassa saa kokemus valinnan vilpittömyydestä. Käytännössä lumilautaileminen on monille laskijoille lajina hyvin kilpailuhenkinen, mutta toisella tavalla niin sanottuun perinteiseen urheiluun verrattuna. Keskeinen ero näiden kahden kilpailemisen ideologian välillä on useimpien tutkimukseeni osallistuneiden lumilautailijoiden mukaan se, että kilpaileminen samalla tavalla kuin lumilautaileminen yleensäkin tapahtuu nimenomaan laskemisen, eikä esimerkiksi voittamisen itsensä vuoksi. (Hänninen 2005.) Hyvä lumilautailija on vapaa, koska hän on valinnut omaehtoisuuden perinteisen kilpaurheilun edustaman pakon sijaan.

\section{VAPAUS ON OMAN KEHON RAJOISSA}

Oppiminen tarjoaa laskijalle mahdollisuuden vapautua omaa ruumista koskevista rajoituksista. Ilmalento nostaa laskijan arkipäiväisen todellisuuden yläpuolelle, jossa painovoima menettää hetkeksi merkityksensä. Vapautuminen merkitsee mahdollisuutta toisenlaisen, aikaisempaan verrattuna vahvemman ja paremman minuuden kohtaamiselle. Muutoksen elementti nousee keskeiseen rooliin myös tässä tulkinnassa. Hyvältä laskijalta edellytetään tiettyä fyysistä suoritustasoa, jossa voima, notkeus ja tasapaino yhdistyvät tekniseen suoritukseen ja tekevät tempusta tai käännöksestä mahdollisen. Tekniikkaa ja laskemisen tyyliä voi hioa loputtomiin, eikä edes ammattilainen ole lumilautailijana koskaan valmis. Oppimisen ideaali onkin yksi lumilautailukulttuurin perustavimmista arvoista:

\section{Hyvä lumilautailija ottaa munt rinteessä liikkeujat huomioon. Hänellä on tarve kehittyä ja myöntää virheensä. Hyvä lumilautailija osaa soveltaa eri tilanteita ja paikkoja tarpeensa mukaan ja osaa toimia oikein tarvittavissa paikoissa. (L1: 186, N84.)}

Tuntureissa ja vuorilla liikkuville vapaalaskijoille (engl. free riding) keskeisintä ei ole useinkaan se, kuinka monta temppua lautailija "pystyy ländäämään" eli laskeutumaan kaatumatta tai onko hän tietoinen half pipe -maailman uusimmista suuntauksista. Tärkeää on sen sijaan tuntea lumen rakenne ja tuulen suunta sekä kyetä arvioimaan, millaisia kiviä tai kantoja valkoisen lumipeitteen alle saattaa olla piiloutuneena. Maastossa lautailtaessa mielenkiintoisina asioina mainitaan uusien kulkemattomien reittien löytäminen ja se, että laskija saa kirjaimellisesti jättää jälkensä sinne, missä kukaan muu ei ole vielä liikkunut. Laskutekniikka on tärkeä turvallisuuskysymys, mutta lumilautailijat liittävät siihen myös vapautta ja laskemisen nautintoa sivuavia merkityksiä. Täydellinen 


\section{VAPAUDEN MERKITYS LUMILAUTAILUKULTTUURISSA}

käännös on pehmeä ja sulava, ja kaikkein mieluisimpia kokemuksia muistellaan vielä vuosia varsinaisen tapahtuman jälkeen. (Vrt. Csikszentmihalyi 1975; 1997; MacAloon \& Csikszentmihalyi 1983.) Laskijan ja ympäristön välinen ero lakkaa hetkeksi olemasta, ja asiat alkavat tapahtua ikään kuin itsestään. Vapaus on vapaalaskijaa kannattelevaa pehmeää puuterilunta ja ilmaa onnistuneen hypyn alla. Kokemuksena se jäsentyy aina "oman kehon rajoissa" (L2: 13, M83) subjektiivisesti:

\section{[...] kaik.ki talvella on hauskaa ja hienoo ja on ihan fililksissä jostain ensimmäi- sistä lumisateista, niin sitten kaikeki mikë liittyy lumeen, niin on jotenkin bienoo ja siellä rinteessä on vaan jotenkin kivaa ... se vaan jotenkin tuntuu bienolta. On siinä sitä vapauden tunnetta ja siinä on jotenkin jännä tunne. Emmä tiedä onko se ton laudan ja sen lumen välissä vai missä se on, mutta jotenkin silleen, että se tuntuu niin bienolta. (T18, N79.)}

Laudan ja lumen välissä tapahtuu jotakin sellaista, mitä on kokemuksena vaikea kuvailla sanoin. Siksi kommunikaatiolle on löydettävä toisenlaisia muotoja. Valokuvaamisessa ja videokuvauksessa sanoja ei tarvita, sillä kokemukset välittyvät ja niitä välitetään suoraan aistihavainnon - tai tarkemmin sanoen jäljittelevän ymmärtämisen - välityksellä lumilautailijalta toiselle. Vaihtoehtoinen tapa omien tuntemusten ja arvojen jäsentämiseksi on lähestyä niitä esimerkiksi rullalautailun tai muiden extreme-lajien kautta ikään kuin kiertoteitse. Käytännössä tämä voi tarkoittaa muun muassa sitä, että laskija vertaa lumilautailemista muihin samankaltaisiin lajeihin, joita hän mahdollisesti myös itse harrastaa.

Ruumiillisen kokemuksen jakaminen verbaalisesti on haastavaa, mutta kokonaan mahdotonta se ei kuitenkaan ole. Haastatteluihin ja lumilautailijoiden tekstimuotoisiin vastauksiin perustuvan tutkimusaineistoni valossa näyttääkin siltä, että vaikka visuaalisuus muodostaa keskeisen osan laskijoiden välistä kommunikaatiota, on myös puhutulla kielellä, johon lumilautailuun liittyvä erityissanastokin viittaa, tärkeä osa lajille tyypillisten kokemusten rakentumisessa. Yhteinen kokemuspohja lumilautailun ja muiden niin sanottujen extreme-lajien, kuten rullalautailun, surffauksen tai vuorikiipeilyn, välillä onkin selkeästi havaittavissa muun muassa tekemiseen liittyvän jännityshakuisuuden, yhteiskunnallisen marginaalisuuden ja erottautumisen tarpeen kautta.

\section{YHTEISKUNNAN PALVELIJOISTA LUOVIKSI KULUTTAJIKSI}

Tyylin kenttä on ilmaisullisesti laaja: se sulkee sisäänsä paitsi arvoihin ja asenteisiin myös pukeutumiseen, musiikkimakuun ja laskemisen tapaan yleisemmin liittyviä elementtejä. Kaikilla laskijoilla, myös aloittelijoilla, on oma henkilökohtainen tapansa liikkua ja olla. Merkitysjärjestelmänä tyyli viittaa kollektiiviseen ja siten yhteisöllisyyttä ylläpitävään toimintaan, jonka ohjaamana yksilöllinen tyyli saa nykyhetkessä realisoituvan muotonsa. Tutkimukseeni osallistuneet lumilautailijat tarkoittavat tyylillä monen- 


\section{RIITTA HäNNINEN}

laisia asioita pukeutumisesta laskemisen tapaan ja jopa laskijan arvoihin ja asenteisiin saakka. Käytännössä yksilöllinen tyyli ei ole kuitenkaan vain yksilön valinta, vaan osa laajempaa yhteisesti jaettua merkitysjärjestelmää.

Leikintutkimuksestaan tunnetulle Helen Schwartzmanille leikkisyys on toiminnan laatuun liittyvää sisäistä motivaatiota, joka tuottaa kulttuurisia merkityksiä. Leikin kyseenalaistava voima on näkyvimmillään erilaisten normirikkomusten yhteydessä, ja esimerkiksi brittiläisessä alakulttuurintutkimuksessa nuorisokulttuureiden tyylillistä ilmaisua on tarkasteltu nimenomaan ritualisoidun vastarinnan näkökulmasta tietyn emokulttuurin puitteissa elävänä yhteiskuntakritiikin muotona (Schwartzman1976, 109-110; Brake 1987, 58-62, 67-72; Pilkington 1994, 8-10, 18-25). Leikin imaginaarisessa maailmassa "vallitseva" järjestellään uudella tavalla niin, että se saa tavanomaisesta poikkeavia merkityksiä, ja juuri siksi esimerkiksi Johan Huizinga (1947, 5, 67,7-8) näkee normirikkomuksia tuottavassa leikkisyydessä voimakkaan kulttuurisen muutosvoiman. Dick Hebdige (1984) tarkastelee vastaavaa ilmiötä alakulttuureiden tyylillisen ilmaisun puitteissa yhteiskunnallisena kommentaarina. Tyyli on tietyn merkitysjärjestelmän ja siihen liittyvien diskurssien puitteissa tapahtuvaa merkkien uudelleen järjestämistä eli rekontekstualisaatiota (bricolage) (ks. Lévi-Strauss 1966; Clarke 1976). Vapaus on tässä asetelmassa leikkisyyden ja autenttisen tyylin elinehto: leikillä ei ole lähtökohtaisesti sen itsensä ulkopuolisia päämääriä, eikä välineellistettyä leikkiä heijastava tyylikään voi siksi olla aitoa.

Lumilautailukulttuurin osalta näyttää siltä, että esimerkiksi oppiminen ja sitä seuraava tyylillinen ilmaisu liittyvät myös kaupallistumista vastustavaan erottautumiseen. Diskursiivisena käytänteenä oppimisen ideaali edustaa lumilautailukulttuurissa laskijoiden keskeisinä kokemia arvoja, eikä se siis näytä palvelevan edellä mainittuja yhteiskunnallisia instituutioita. Ongelmalliseksi funktionalistisen ajattelumallin tekee tässä se, että suuntaus nostaa erilaiset konfliktit lumilautailukulttuuria hallitsevaksi arvoksi, jolloin laskijan henkilökohtainen kokemus jää helposti länsimaisen yhteiskunnan rakenteelliselle tasolle sijoittuvien kysymysten varjoon:

Nykyään vain toivoisin, että löytäisin edes kerran viikossa semmoisen olon, että on todella energinen olo ja tekee mieli bullutella tai yrittää unsia asioita. Olen nyt 19vuotias ja jo tässä vaiheessa kaipaa tietynlaista nuorundenintoa. 10 vuotta laskeneena suurin kehitys on jo tapabtunut. Joka kerta rinteeseen mennessä vapauden tunne on kuitenkin parasta. Siitähän lautailussa oli alunperinkin kysymys. Ei kapinoinnista tai bulluudesta, vaan vapauden tunteesta. (L1: 157: M83.)

Henkilökohtaisten kokemusten merkitykseen on kiinnittänyt huomiota myös nuorten arkipäivää ja kulutustottumuksia tutkinut Paul Willis, jonka mukaan kaupallisen populaarikulttuurin keskellä elävät brittinuoret ovat kaikkea muuta kuin passiivisia kuluttajia tai tietyn työväenluokkaisen emokulttuurin yhteiskunnallisia epäkohtia heijastelevia peilipintoja. Rakenteellisten seikkojen sijaan Willis haluaa korostaa kuluttamiseen liitettyjen merkitysten luovaa, spontaania ja nuorten omasta elämismaailmasta arvonsa ammentavaa erityisluonnetta. (Willis 1993, 86; vrt. Willis 1978, 170-171.) Uudet, tavanomaisesta poikkeavat merkitykset, joita esimerkiksi tyyli ja 


\section{VAPAUDEN MERKITYS LUMILAUTAILUKULTTUURISSA}

tietyn tyylin mukainen kuluttaminen lumilautailukulttuurissa edustavat, muodostavat Willisille keskeisen osan arjen luovaa demokratiaa. Henkilökohtaisen tyylin merkitystä korostava diskurssi esittää tekemisen omaehtoisuuden muuten yhteisesti jaettujen merkitysten laskijakohtaisina tulkintoina. Yksilöllisyys ja yhteisöllisyys esiintyvät tässä asetelmassa perinteisten vastakkainasettelujen ja instituutioiden yläpuolelle nousevana vastavuoroisena käsiteparina.

\section{ITSEILMAISUN DEMOKRATIAA}

Aika rap pukeutumistyylihän mulla varmaan on. laskutyylistä mä en osaa sanoa mitään. rento? Ehkä. Toivottavasti. (L1: 131, M83.)

Lumilautailussa koetaan tärkeäksi, että jokaisella on näkökulmasta riippuen joko vapaus ja sitä kautta osittain jopa velvollisuus valita oma tapansa olla lumilautailija. Laskijat kuvaavat pukeutumistaan ja elämäntapaansa tyypillisesti rennoksi. Käytännössä rento voi tarkoittaa laskijasta riippuen monia asioita löysistä vaatteista arkielämään kohdistuvaan huolettomuuteen ja näitä kahta yleisemmällä tasolla yhdistävään vapauteen toteuttaa itseään paitsi rinteessä myös muilla elämänalueilla:

\section{Minulle lautailusta on tullut elämäntapa. Kun tekee jotain muntakin niin sitä tekee yleensä juuri sen vuoksi että se on hauskaa. Ottaa asioita paljon rennommin eikä stressaa jokaisesta pienemmästäkin asiasta. Tuntuu että ibmisenäkin olen jotenkin vahvempi. (L1: 125, N83.)}

Dick Hebdigen (1984, 102-103; vrt. Clarke 1976, 179) mukaan tyyli paljastaa alakulttuurin salaisen "identiteetin" eli sen, millaisia arvoja se edustaa ja vastustaa suhteessa niihin instituutioihin, joista se haluaa erottautua. Tyylillinen kommunikaatio tuottaa vallitsevien järjestysten sisällä ja niiden rinnalla eläviä vaihtoehtoisia maailmoja, jotka tosin määrittyvät usein vastavuoroisesti toinen toistensa kautta. (Becker 1963.) Myös lumilautailukulttuuri käyttää muiden merkitysjärjestelmien rakenteita oman kommunikaationsa raaka-aineina. Kaupallistumisen kaltaisten ilmiöiden vuoksi tyylillisessä ilmaisussa on mukana paljon länsimaista yhteiskuntaa yleisellä tasolla kommentoivaa kritiikkiä, mutta myös muihin nuorisokulttuurisiin suuntauksiin, kuten esimerkiksi rullalautailuun viittaavia myönteisiä samastumisenkohteita:

Parasta on oppia jotain untta ja kehittyä. Vaikean tempun onnistunut laskeutumi-
nen on upea tunne. Tietysti on myös mahtavaa laskea hiljaisundessa yksikseen peh-
meällä punterilla [vastikään satanutta koskematonta lunta]. Kokemukset ovat
ainutlaatuisia, omaan suoritukseen liittyviä hyvänolontunteita. Ehkä skeittankesessa
onnistuminen on verrattavissa lumilautailun onnistumiseen. (L2: 66, M84.)

Lumilautailukulttuurissa tyylillä tarkoitetaan yleisesti ottaen sitä tapaa tai asennetta, jolla laskija ilmaisee itseään. Keskeiseksi kysymykseksi tyylillistä ilmaisua tarkasteltaessa 


\section{RIITTA HäNNINEN}

nousee se, millaisista asioista sen välityksellä halutaan puhua. Omaperäisyys ja luovuus ovat sosiaalisesti tärkeitä arvoja, jotka korostavat laskukokemuksen ja -tyylin yksilöllisyyteen nojaavaa suvaitsevaisuutta. Uusien asioiden opetteleminen on sekä laskijan että koko lumilautailukulttuurin kannalta keskeinen arvo. Myös riskinhallinta kuvastaa harkinnan ja itsetuntemuksen merkitystä oppimisprosessissa. Kilpailemisessa tärkeintä on tulla paremmaksi lautailijaksi, ja voiton sijaan monet laskijat tavoittelevatkin mukavaa fiilistä ja rentoa meininkiä. Hyvä lautailija ei ammenna toimintansa päämääriä perinteisen urheilun suorituskeskeisestä kaupallisuudesta vaan kokee asettavansa itse omat tavoitteensa:

Lautailu on kaikkea. Se on urheilun yläpuolella. Vaikka se on urheilua, mutta se on ainoa laji mulle, jota ei tarvitse harrastaa kunnon tai pakollisen vääntämisen takia, vaan siksi että siitä tulee niin älyttömän byvä filis, vapauden ja elämisen tunne. (L2: 129, N 84.)

Vapauden käsite jäsentää ja perustelee lumilautailukulttuurin ideologista perusrakennetta ja luo samalla pohjan preskriptiiviselle eli tiettyä arvojärjestelmää ylläpitävälle ilmaisulle. Se, mitä lumilautailukulttuurissa kutsutaan vapaudeksi, on aina vapautta jostakin - tai vaihtoehtoisesti vapautta johonkin (Berlin 1969). Vapauden kulttuuriset merkitykset ovat tässä asetelmassa siis joko-tai: kielteistä vapautta jostakin pois päin tai myönteisesti vapautta kohti jotakin. Vapaa-aikanaan lautailevalle harrastelijalle laskeminen tarjoaa hengähdystauon kiireisen työelämän keskellä, ja vaikka laskeminen ulkoa käsin tarkasteltuna täyttäisikin työn tunnusmerkit, saattaa esimerkiksi ammattilainen kokea sen kokonaisvaltaisemmin elämäntavakseen. Lumilautaileminen voi merkitä myös luovuutta, itseilmaisua, oppimista, vauhdinhurman siivittämää jännitystä, hauskanpitoa, omaehtoista harrastusta, tyylillistä esikuvaa, kavereita, yhdessäoloa, uutta jännittävää trendi-ilmiötä ja joillekin laskijoille jopa eräänlaista "hengellistä" kokemusta.

Duncan Humphreys kuvaa lumilautailukulttuurin ideologista menneisyyttä 1960-luvun beatnik-filosofian puitteissa itseilmaisullisen demokratian kultakaudeksi, johon liittyi myös kaupallisuutta ja massatuotantoa kritisoineita punk-vaikutteita. Punk-ideologia kritisoi "beatnikkeja" ja hippien kukkaissukupolvea siitä, että ne olivat menettäneet uskottavuutensa sopeutumalla siihen kapitalistiseen yhteiskuntajärjestykseen, jota ne aikaisemmin kritisoivat. Punk-liike rehabilitoi kulttuurisen luovuuden siirtämällä sen bourdieaulaisesta eliitistä "koko kansan" jokapäiväistä arkea demokraattisesti määrittäväksi arvoksi. (Humphreys 2003, 412-413; Bourdieau 1984, 13-14, 318.) Lumilautailukulttuurissa 1960-luvun "uusi urheilu" ja sen myötä 1990-luvulla yleistyneiden extreme-lajien vaikutus näkyy juuri tekemisen omaehtoisuutta ja yksilöllistä tyyliä korostavina diskursseina. Humphreysin aatehistoriallisesta johdannosta tekee valaisevan edelleen se, että se antaa suomalaisen lumilautailun paikallisille muodoille maailmanlaajuisesti levinneeseen globaaliin merkitysjärjestelmään perustuvan tulkintakehyksen.

Vapauden kulttuurisiin merkitysrakenteisiin punkin vaikutus heijastuu lumilautailukulttuurin osalta juuri "do-it-yourself"-tyyppisenä, tekemisen omaehtoisuutta 


\section{VAPAUDEN MERKITYS LUMILAUTAILUKULTTUURISSA}

korostavana diskurssina. Punk-ideologia elää yksilöllistä tyyliä ja "oikeaa asennetta" kostavissa tulkinnoissa lajin kaupallistumisesta huolimatta vielä tänäkin päivänä. Vastaava asetelma on havaittavissa myös monien lumilautailukulttuuriin vaikuttaneiden ala- ja nuorisokulttuuristen suuntausten välillä. Lumilautailukulttuuri ikään kuin lainaa ja uudelleen sovittaa omaan ideologiaansa mahdollisesti jopa 1950- ja 1960-luvuilta peräisin olevia arvorakenteita ja ilmaisumuotoja. Keskeistä kaikille myönteisille viittauskohteille on kuitenkin vapauden kokemus, joka jäsentyy lumilautailukulttuurissa aina laskijan henkilökohtaisen kokemuksen kautta.

\section{VIITTEET}

1. Tutkimukseeni osallistuneiden lumilautailijoiden sukupuoli $(M / N)$ ja syntymävuosi (esim. 87) on merkitty sitaattien yhteyteen informantin ilmoittamalla tarkkuudella. Aineistokuvauksessa mainitsemani artikkeliaineisto koostuu suomalaisissa tiedotusvälineissä vuosien 1984-2005 aikana julkaistuista lehti- ja Internet-artikkeleista. Yllä kuvatusta tutkimusaineistosta olen merkinnyt lähdeluetteloon sitaateissa lainaamani aineistolähteet. Varsinainen analyysi perustuu aineiston laajuuden vuoksi teemahaastatteluiden ja kyselylomakeaineistojen pohjalta tekemiini muistiinpanoihin.

2. Teemahaastattelurungon perusrakenne jakautuu lomakekyselyssä 1 (L1) ja lomakekyselyssä 2 (L2) esitettyihin kysymyksiin. Ensimmäisessä kyselyssä tiedustelin lumilautailijoilta henkilö- ja taustatietoja ja sitä, missä ja kuinka usein he lautailevat. Kysyin, onko lumilautailu heidän mielestään urheilua, ja jos, niin miten he näkemystään perustelevat. Halusin tietää myös, millaisia ominaisuuksia laskijat arvostavat hyvässä lumilautailijassa. Pyysin heitä kuvailemaan omaa pukeutumistaan ja lumilautailutyyliään ja siinä mahdollisesti tapahtuneita muutoksia. Laskijat kertoivat myös, miten lumilautaileminen näkyy heidän muussa elämässään. Lopuksi he kuvailivat sitä, mitä he mahdollisesti haluaisivat kieltää lumilautailukulttuurissa sekä edelleen sitä, minkä he kokevat lajin puitteissa kaikkein tärkeimmäksi asiaksi. Lomakkeen viimeisessä osiossa kysyn vielä, millaisia asioita lumilautailija tekisi, jos hän ei syystä tai toisesta voisi enää harrastaa lumilautailua. Molempien kyselylomakkeiden lopussa on mahdollisuus jatkaa vastaustaan omavalintaisilla aiheilla. Kyselylomakkeen toisessa versiossa tiedustelin tutkimukseeni osallistuneilta lumilautailijoilta, harrastavatko heidän ystävänsä lumilautailua ja voiko lumilautailijaa erottaa kadulla muista vastaantulevista ihmisistä. Lumilautailijat kertoivat myös uudelleen pukeutumisestaan sekä lumilautailukulttuurin kielenkäytöstä ja laskijoiden käyttäytymisestä. Kysyin myös, onko lumilautailijoiden välillä eroja tai muodostavatko laskijat erityisiä ryhmittymiä. Lomakkeessa käsiteltiin myös lumilautailua koskevan uutisoinnin seuraamista, lumilautailuun liitettyjä kokemuksia ja mahdollista "filosofiaa", jota lumilautailijat toteuttavat omassa laskemisessaan.

3. "Half pipe" taipuu suomalaisittain paipiksi, joka on erilaisia trikkejä (engl. trick) eli temppuja varten rakennettu halkaistua putkea muistuttava luminen kouru. Boksilla (engl. box) tarkoitetaan vastaavasti suurikokoisia, jyrkällä alastulolla varustettuja 


\section{RIITTA HäNNINEN}

hyppyreitä, jotka palvelevat niin ikään hyppimisestä ja "isoista ilmoista" eli korkealle nousevista tempuista innostuneita laskijoita. Viime vuosina yleistyneessä reilauksessa (engl. hand rail) laskija liukuu erilaisten laskettelurinteeseen rakennettujen kaiteiden tai muiden esteiden päällä.

\section{LÄHTEET}

\section{Tutkimusaineistot}

Lehdet:

Pohjolan Beach boy. - Skimbaaja (1984): 2, 38-39.

Teemahaastattelut ( $\mathrm{T})$ :

Teemahaastattelurunko "Suomalainen lumilautailukulttuuri" vuodelta 2002-2003. Haastattelija: Riitta Hänninen. Haastattelunauhat ja litteraatiot ovat haastattelijan hallussa.

— T18, N79: nainen, 23 vuotta. Kotipaikka Helsinki. Haastateltu 23.11.2002.

— T30, M78: mies, 25 vuotta. Kotipaikka Helsinki. Haastateltu 4.2.2003.

Lomakekyselyaineistot (L):

Haastattelurunko 1 (L1)

"Tarinoita ja sattumuksia lumilautailun maailmasta 1" aikajaksona 22.10.2002_ 28.10.2002. ( $n=186$ ). Julkaistu Internetissä lumilautailusivustoilla Droppi.net ja Nolla.net. Kyselyn laatija: Riitta Hänninen. Aineisto tekijän hallussa.

— L1: 12; M75: mies, 27 vuotta. Kotipaikka Kotka. Vastaus 22.10.2002.

- L1: 116, N85: nainen, 17 vuotta. Kotipaikka Lappeenranta. Vastaus 25.10.2002.

- L1: 125, N83: nainen, 19 vuotta. Kotipaikka Kuopio. Vastaus 26.10.2002.

— L1: 186, N84: nainen, 18 vuotta. Kotipaikasta ei tietoa. Vastaus 29.10.2002.

Haastattelurunko 2 (L2)

"Tarinoita ja sattumuksia lumilautailun maailmasta 2" aikajaksona 28.10.20028.1.2003. ( $\mathrm{n}=559)$. Julkaistu Internetissä lumilautailusivustoilla Droppi.net ja Nolla. net. Kyselyn laatija: Riitta Hänninen. Aineisto tekijän hallussa.

— L2: 13, M83: mies, 19 vuotta. Kotipaikka Helsinki. Vastaus 19.10.2002.

— L2: 501, M80: mies, 23 vuotta. Kotipaikka Tampere. Vastaus 1.1.2003.

— L2: 66, M84: mies, 18 vuotta. Kotipaikka Kairala. Vastaus 4.11.2003. 


\section{VAPAUDEN MERKITYS LUMILAUTAILUKULTTUURISSA}

\section{Opinnäytteet, julkaisemattomat}

MANNERMAA, JAAKKO 2004: Oudosta ilmiöstä seuratuksi urbeiluksi. Lumilautailu Helsingin Sanomissa ja Iltalehdessä 1988-2003. Journalistiikan pro gradu -tutkielma. Jyväskylä: Jyväskylän yliopisto, viestintätieteiden laitos.

\section{Kirjallisuus}

BECKER, HOWARD 1963: Outsiders. Studies in the Sociology of Deviance. London: The Free Press of Glencoe.

BERLIN, ISAIAH 1969: Four Essays on Liberty. Oxford: Oxford University Press.

BRAKE, MICHAEL 1987: Comparative Youth Culture. The Sociology of Youth Culture and Youth Subcultures in America, Britain and Canada. London: Routledge.

BOURDIEAU, PIERRE 1984: Distiction: a Social Critique of the Judgement of Taste. London: Routledge \& Kegan Paul.

CAILLOIS, ROGER 1961: Man, Play, and Games. New York: Free Press of Glencoe.

CHRISTENSEN, OLAV 1999: The Playing Collective. Snowboarding. Youth Culture and the Desire for Excitement. - Ethnologia Scandinavica 29: 106-119.

- 2001a: Absolutt Snowboard. Studier i sidelengs ungdomskulturer. Oslo: Universitetet i Oslo.

— 2001b: Absolutt Snowboard. Kampen mot kjedsombeten. Oslo: Gyldendal Norsk Forlag.

- 2002: The Tales of the Tribes - Communication and Consumption in Snowboard Culture. - Hauan, Marit Anne \& Heggli, Gry (eds.), Younger Than Yesterday, Older Than Tomorrow. NNF Publications 1. Turku: Nordic Network of Folklore.

CLARKE, JOHN 1976: Style. - Hall, Stuart \& Jefferson, Tony (eds.), Resistance through Rituals. Youth Subcultures in Post-War Britain. London: Hutchnson \& Co.

CSIKSZENTMIHALYI, MIHALY 1975: Beoynd Boredom and Anxiety. The Experience on Play in Work and Games. San Fransisco: Jossay-Bass Publishers.

— 1997: Finding Flow. The Psychology of Engagement with Everyday Life. New York: Basic Books.

FEATHERSTONE, MIKE 1990: Global Culture: An Introduction. - Featherstone, Mike (ed.), Global Culture. Nationalism, Globalization and Modernity. A Theory \& Culture Society Special Issue. London: Sage Publications.

GELDER, KEN \& THORNTON, SARAH (eds.) 1997: The Subcultures Reader. London: Routledge.

HALL, STUART 1999: Identiteetti. Tampere: Vastapaino.

HEBDIGE, DICK 1984: The Meaning of Style. London: Methuen.

HEISKANEN, ILKKA \& MITCHELL, RITVA 1985: Lättähatuista punkkareibin: suomalaisen valtakulttuurin ja nuorisokulttuurien kobtaamisen kolme vuosikymmentä. Helsinki: Otava.

HUIZINGA, JOHAN 1947: Leikkivä ihminen (bomo ludens). Yritys kulttuurin leikkiaineksen määrittelemiseen. Helsinki: WSOY. 


\section{RIITTA HÄNNINEN}

HUMPHREYS, DUNCAN 1996: Snowboarders: Bodies out of Control and in Conflict. - Sporting Traditions 13: 1, 3-23.

- 1997: "Shreadheads Go Mainstream?" - Snowboarding and Alternative Youth. International Review for the Sociology of Sport 32: 2, 149-160.

— 2003: Selling out Snowboarding. The Alternative Response to

Commercial Co-optation. - Rinehart, Robert \& Sydnor, Synthia (eds.), To the Extreme. Alternative Sports, Inside and Out. New York: State University of New York Press.

HÄNNINEN, RIITTA 2003: Leikki. Ilmiöja käsite. Nykykulttuurin tutkimuskeskuksen julkaisuja 76. Jyväskylä: Nykykulttuurin tutkimuskeskus.

- 2004: Snowboarding Culture and the Totality of Style. - Ethnologia Scandinavica 34: 75-88.

- 2005: Perinteisen urheilun tuolla puolen. Lumilautailukulttuuri ja puuterilumen lumo. - Kulttuurintutkimus 22: 1, 33-46.

LÉVI-STRAUSS, CLAUDE 1966: The Savage Mind. Chicago: The University of Chicago Press.

MACALOON, JOHN \& CSIKSZENTMIHALYI, MIHALY 1983: Deep Play and the Flow Experience in Rock Climbing. - Harris, Janet C. \& Park, Roberta (eds.), Play, Games and Sports in Cultural Contexts. Champaign: Human Kinetics Publishers.

PEARSON, KENT 1979: Surfing Subcultures of Australia and New Zealand. St. Lucia: University of Queensland Press.

PILKINGTON, HILARY 1994: Russia's Youth and its Culture. A Nation's Constructors and Constructed. London: Rougledge.

RINEHART, ROBERT 2003: Dropping into Sight. Commodification and Co-optation of In-line Skating. - Rinehart, Robert \& Sydnor, Synthia (eds.), To the Extreme. Alternative Sports, Inside and Out. New York: State University of New York Press.

SCHWARTZMAN, HELEN 1976: Research on Children's Play: an Overview, and Some Predications. - Stevens, Phillip Jr. (ed.), Studies in the Anthropology of Play: Papers in Memory of B. Allan Tindall. Proceedings of the Second Annual Meeting of the Association for the Anthropological Study of Play. West Point: Leisure Press.

WILLIS, PAUL 1978: Profane Culture. London: Routledge \& Kegal Paul.

- 1993: Common Culture. Milton Keynes: Open University Press.

Filosofian lisensiaatti Riitta Hänninen valmistelee etnologian väitöskirjaa Jyväskylän yliopistossa. 